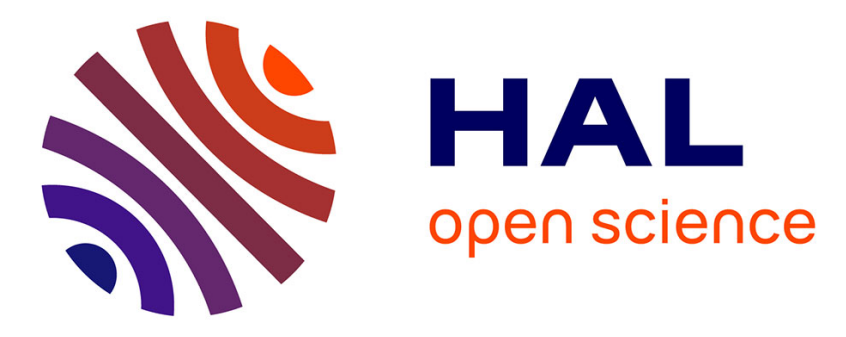

\title{
Bridging the gap between academic and industrial hydrocracking: on catalyst and operating conditions effects
}

Pedro Freitas Mendes, João M Silva, Filipa Ribeiro, Antoine Daudin, Christophe Bouchy

\section{To cite this version:}

Pedro Freitas Mendes, João M Silva, Filipa Ribeiro, Antoine Daudin, Christophe Bouchy. Bridging the gap between academic and industrial hydrocracking: on catalyst and operating conditions effects. Catalysis Science \& Technology, 2020, 10 (15), pp.5136-5148. 10.1039/d0cy00568a . hal-02978144

\section{HAL Id: hal-02978144 \\ https://hal-ifp.archives-ouvertes.fr/hal-02978144}

Submitted on 26 Oct 2020

HAL is a multi-disciplinary open access archive for the deposit and dissemination of scientific research documents, whether they are published or not. The documents may come from teaching and research institutions in France or abroad, or from public or private research centers.
L'archive ouverte pluridisciplinaire HAL, est destinée au dépôt et à la diffusion de documents scientifiques de niveau recherche, publiés ou non, émanant des établissements d'enseignement et de recherche français ou étrangers, des laboratoires publics ou privés. 
4 Pedro S. F. Mendes ${ }^{a, b, 1 *}$, João M. Silva ${ }^{a, c}$, M. Filipa Ribeiro ${ }^{a}$, Antoine Daudin, 5 Christophe Bouchy ${ }^{\text {t* }}$

\section{Bridging the gap between academic and industrial} hydrocracking: on catalyst and operating conditions effects

\author{
${ }^{a}$ Centro de Química Estrutural and Departamento de Engenharia Química, Instituto Superior \\ Técnico, Universidade de Lisboa, Av. Rovisco Pais, 1049-001 Lisboa, Portugal
}

${ }^{b}$ IFP Energies nouvelles, Rond-point de l'échangeur de Solaize, BP 3, 69360 Solaize, France

${ }^{c} A D E Q-I S E L$, Instituto Superior de Engenharia de Lisboa, Instituto Politécnico de Lisboa, $R$. Cons. Emídio Navarro, 1959-007 Lisboa, Portugal

*pedro.f.mendes@tecnico.ulisboa.pt; christophe.bouchy@ifpen.fr ; +33 (0)4 37702989

\section{Abstract}

This work aims at bridging the knowledge gap between the well-studied Pt/zeolite catalysts and the industrially-employed NiMoS/( $\mathrm{Al}_{2} \mathrm{O}_{3}+$ zeolite) ones. To do so, catalyst series based on HUSY zeolite were evaluated in the hydroconversion of $n$-hexadecane under similar operating conditions, but the industrially-relevant $\mathrm{H}_{2} \mathrm{~S}$ and $\mathrm{NH}_{3}$ contaminants were added when evaluating the latter. The intrinsic performance of $\mathrm{Pt} / \mathrm{HUSY}$ and $\mathrm{NiMoS} /\left(\mathrm{Al}_{2} \mathrm{O}_{3}+\mathrm{HUSY}\right)$ catalysts was noticeably similar, when well-balanced, with the catalytic activity being however much lower in the latter (temperature gap of $120 \mathrm{~K}$ ). Ammonia inhibition of more than $99 \%$ of the protonic sites was revealed to be at the origin of such low activity. On the other hand, the metal-acid balance was only reached at sufficiently low reaction temperatures (ca. $593 \mathrm{~K}$ ), i.e. when the $\mathrm{NH}_{3}$ inhibiting effect increased the metal to acid sites ratio in the $\mathrm{NiMoS} /\left(\mathrm{Al}_{2} \mathrm{O}_{3}+\mathrm{HUSY}\right)$ to values five orders of magnitude larger than in the $\mathrm{Pt} / \mathrm{HUSY}$ one. In addition to the understanding achieved on the role of metal-acid balance in industrial-like catalysts and its key controlling parameters, these findings also point to the need of developing better hydrogenating functions to improve the efficiency, and consequently the sustainability, of liquid fuels production.

Keywords: industrial hydrocracking, metal-acid balance, HUSY zeolite, inhibition.

\footnotetext{
${ }^{1}$ Present address: Laboratory for Chemical Technology, Ghent University, B-9052 Ghent, Belgium.
} 


\section{$1 \quad 1$ Introduction}

2 The actual energy context as well as recent forecasts ${ }^{1}$ sustain the preeminent role of 3 hydrocracking (HCK) in modern conversion of heavy low-quality feedstocks into lighter high4 quality middle distillates fuels, particularly jet fuel, and also base chemicals for industry. This 5 conversion occurs in presence of a bifunctional catalyst which plays thus a key role on the HCK 6 process performances. Therefore, adequate catalyst design and optimization can have major 7 impact in the sustainability of this process.

8 HCK processes are carried out under hydrogen pressure and in the presence of a 9 heterogeneous catalyst. Nowadays, the main feedstock for HCK is straight run distillation 10 vacuum gas oil (VGO) that may be mixed with other heavy feeds ${ }^{2}$. VGO is mainly composed by aromatic and paraffinic compounds with a wide range of molecular weights. Other elements besides carbon and hydrogen can also be found on VGO. Sulphur and nitrogen are commonly presented in polyaromatic molecules, which can also contain metals in trace amounts ${ }^{2}$. To remove such impurities, an initial hydrotreating step is required, generating a more hydrogenated stream rich in $\mathrm{H}_{2} \mathrm{~S}$ and $\mathrm{NH}_{3}$. In single-stage processes, this stream is directly fed to the hydrocracking reactor without any intermediate separation ${ }^{3}$.

The HCK catalysts are bifunctional catalysts, i.e. featuring two catalytic functions: a hydrogenation-dehydrogenation $(\mathrm{HDH})$ function and an acidic function ${ }^{2-4}$. In presence of $\mathrm{H}_{2} \mathrm{~S}$, the $\mathrm{HDH}$ function is commonly granted by a transition metal sulfide (TMS) promoted with other metals (commonly, Mo or $\mathrm{W}$ promoted with either $\mathrm{Ni}$ or $\mathrm{Co}$ ), because noble metals, e.g. platinum, are strongly inhibited by sulfur compounds ${ }^{5}$. The acidic function can be provided by amorphous silica-aluminas or zeolites, in particular the ultrastabilized Y zeolite (HUSY), usually shaped with an alumina binder ${ }^{2,3}$. The selection of the acid function is governed by the desired product carbon chain range and process type as well as the nitrogen content in the feed. Zeolite based catalysts show a high activity (owing to high Brønsted acid strength), high thermal/hydrothermal stability, good resistance to poisoning, and low coking rate resulting in a good performance and long catalyst life ${ }^{6,7}$.

Most of the academic studies have been conducted over zeolite-supported platinum catalysts, which are typically evaluated in the hydroconversion of pure $n$-alkanes. As a result, a panoply of evermore tuneable acidic functions is available nowadays ${ }^{7-10}$. More importantly, the (bifunctional) reaction mechanism ${ }^{11,12}$ in these simplified laboratorial bench systems has been understood at its fundamental level. Particularly, for a given acidic function, feedstock, and operating conditions, the catalytic behaviour is known to depend on the balance (i.e. ratio of activity) ${ }^{13,14}$ and intimacy (i.e. distance) ${ }^{15,16}$ between the hydrogenating and Brønsted acid sites. For selected feed and reaction conditions, catalyst performances are optimal when catalyst functions are well-balanced and intimacy is adequate ${ }^{11,16,17}$. The activity and (e.g. 
hydroisomerization) selectivity are then essentially dictated by the properties of the acid

2 function, i.e. are intrinsic to the selected acid function.

3 In contrast, studies with industrial-like catalysts and feedstocks, i.e. featuring promoted TMS

4 supported on shaped zeolites and feedstocks replicating industrial ones, are much less

5 frequent. More importantly, the focus is often held on the evaluation of industrial performances

$6{ }^{18}$, comparing different catalysts ${ }^{19-24}$, typically at optimal operating conditions, but rarely

7 providing fundamental insights into the industrial-like systems. The great complexity of industrial

8 feedstocks together with the lack of information (due to confidential clauses) on industrial

9 catalysts further hinders the understanding of these systems. In the same way, only a few

10 studies compare laboratorial and industrial catalysts, but the focus is in any case put on the

11 performances. For instance, the phenanthrene hydroisomerization selectivity over promoted

$12 \mathrm{MoS}_{2}$ /zeolite catalytic system was found to be poorer than Pt/zeolite ones, but the influence of 13 the metal-acid balance was not taken into account ${ }^{25}$. The same conclusion was reached via 14 kinetic modelling over a $\mathrm{MoS}_{2} /\left(\mathrm{HBEA}+\mathrm{Al}_{2} \mathrm{O}_{3}\right)$ catalyst (in this case for $n$-hexadecane), but once 15 again no characterization of the active sites was performed ${ }^{26}$.

In brief, in-depth rationalization of industrial-like catalysts and their behaviour in hydrocracking is still lacking in the open literature. In addition, the state-of-the-art understanding on hydroconversion is based on investigations at laboratorial conditions. The aim of this work is hence twofold. First, to characterize, at the active site level, and second to rationalize the behavior of industrial-like catalysts in hydroconversion under operating conditions as comparable as possible to those commonly used in industry. The ultimate goal is to unveil the similarities and differences between the poorly-studied industrial-like catalytic systems and the typical laboratorial catalytic systems. As the comprehension of individual phenomenon, particularly at the active site level, under industrial-like conditions is virtually impossible, a reduction of the complexity in the system under study is required. As the focus of this work is hold at the catalytic system, the feedstock will be as simple as possible to be somehow representative of reactions occurring in hydrocracking reactors. The simplest model molecules among the ones present in VGO are long chain $n$-alkanes. A molecule of particular interest is then $n$-hexadecane, as it is been widely studied in literature as well. Moreover, $\mathrm{H}_{2} \mathrm{~S}$ and $\mathrm{NH}_{3}$ will be present in the reaction medium, to reproduce of the effect of contaminants in industrial reactors.

Concerning the catalysts formulation, HUSY zeolite was selected as acid function as this zeolite is widely used in industrial hydrocracking catalysts. The laboratorial catalyst consist hence of noble metal over HUSY powder labelled Pt/HUSY, which formulation was previously optimized 13. The industrial-like catalysts feature a Ni-promoted molybdenum sulphide (NiMoS) phase as $\mathrm{HDH}$ function loaded into extrudates of alumina-bound HUSY zeolite, labelled $\mathrm{NiMoS} /\left(\mathrm{Al}_{2} \mathrm{O}_{3}+\mathrm{HUSY}\right)$. A preliminary study on catalysts with different molybdenum loadings was firstly performed and a catalyst was selected based on the observed performances. 


\section{1 \\ 2 Materials and Methods}

\section{$2 \quad 2.1$ Zeolite and catalyst preparation}

3 Zeolite HUSY (CBV720) was supplied by Zeolyst. The framework was previously identified as of 4 type FAU and the global and framework silicon to aluminium molar ratio were determined to be 516.7 and 18.4, respectively ${ }^{27}$. Pt/HUSY catalyst was prepared by incipient wetness 6 impregnation of $0.7 \mathrm{wt} . \%$ of platinum according to a protocol published elsewhere ${ }^{27}$. The 7 impregnated material was dried overnight at $383 \mathrm{~K}$. Calcination under continuous air flow (4 NL $8 \mathrm{~h}^{-1} \mathrm{~g}^{-1}$ ) consisted of three plateaux at 423,523 and $623 \mathrm{~K}$ over $1 \mathrm{~h}$ each and a final plateau at $9773 \mathrm{~K}$ over $2 \mathrm{~h}$. Ex-situ reduction under hydrogen flow $\left(4 \mathrm{NL} \mathrm{h}^{-1} \mathrm{~g}^{-1}\right)$ included two plateaux: 393 $10 \mathrm{~K}$ over $1 \mathrm{~h}$ and $723 \mathrm{~K}$ over $2 \mathrm{~h}$. A heating rate of $5 \mathrm{~K} \mathrm{~min}^{-1}$ was used in all cases.

The shaped support was prepared by mixing-extrusion of HUSY (CBV720) with boehmite employing a procedure published elsewhere ${ }^{28}$. The metals were introduced in the calcined support by incipient wetness impregnation with an aqueous solution of $\mathrm{H}_{3} \mathrm{PO}_{4}, \mathrm{Ni}(\mathrm{OH})_{2}$ and $\mathrm{MoO}_{3}$. Catalysts with three different Mo contents were prepared, while the nickel and phosphorous to molybdenum (atomic) ratios were kept constant at 0.40 and 0.48 , respectively. Further details on the preparation protocols can be found in a previous work ${ }^{29}$. After a maturation step, the material was then dried overnight at $493 \mathrm{~K}$ and calcined under air flow (1.5 $\mathrm{NL} \mathrm{h} \mathrm{g}^{-1}$ ) at $723 \mathrm{~K}$ over $2 \mathrm{~h}$ (heating at $5 \mathrm{~K} \mathrm{~min}^{-1}$ ). Ex-situ sulphidation was carried out over a part of the samples in order to characterize the NiMoS phase. The sulphidation took place at $623 \mathrm{~K}$ over $2 \mathrm{~h}$ (heating at $5 \mathrm{~K} \mathrm{~min}^{-1}$ ) under a $\mathrm{H}_{2} / \mathrm{H}_{2} \mathrm{~S}$ flow (15 vol.\%) of $1.5 \mathrm{NL} \mathrm{h}^{-1} \mathrm{~g}^{-1}$ and the samples were sealed under a $\mathrm{N}_{2}$ atmosphere. Throughout this article, calcined samples will be denoted NiMo and sulphided samples will be denoted NiMoS.

\subsection{Materials characterization}

Both the HUSY zeolite and the Pt/HUSY catalyst have been extensively characterized in preceding works ${ }^{13,27,30}$. The HUSY shaped support has been also characterized in detail elsewhere ${ }^{28}$. Concerning the NiMo-based catalysts, a summary of the techniques employed is provided below, with the focus being held on the determination of the amount of active NiMoS sites. Additional details are provided on the referred works and in section SI.3 of the Supporting Information.

Quantitative elemental analysis was performed by x-Ray Fluorescence (XRF). Samples were grinded and sieved into a granulometry under $200 \mu \mathrm{m}$. Measurements were carried out directly over powder samples in a Thermofischer Scientific Advant-X instrument. The micrometric elemental distribution was assessed via electron probe micro analysis (EPMA), carried out in a JEOL JXA 8100 equipment. The detailed procedure can be found elsewhere ${ }^{29}$ (vide SI.3 for a 
summary). The $\mathrm{MoS}_{2}$ slab length was measured by transmission electron microscopy (TEM) ${ }^{29}$, using a JEOL JEM $2100 \mathrm{~F}$ microscope operated at $200 \mathrm{kV}$.

X-ray photoelectron spectroscopy (XPS) was carried out in a ESCA KRATOS Axis Ultra spectrometer following a previously published procedure ${ }^{29}$. The atomic Ni/Mo ratio of $\mathrm{MoS}_{2}$ slabs was calculated as the product of the bulk Ni fraction (by XRF) multiplied by the fraction of $\mathrm{Ni}$ atoms involved in the NiMoS phase divided by the product of the bulk Mo fraction (by XRF) multiplied by Mo atoms corresponding to $\mathrm{MoS}_{2}$. The molar amount of mixed sites per gram of sulfided catalyst ( $\mathrm{n}_{\text {Nimos }}$ ) was calculated based on the weight fraction of $\mathrm{Ni}$ in the sample measured by XRF $\left(x_{N i}\right)$ along with the fraction of Ni engaged in the NiMoS sites $\left(x_{N i_{N i M O S}}\right)$ as estimated by XPS and the atomic mass (AM) of nickel (Eq. 1).

$$
n_{N i M o S}=\frac{x_{N i} \times x_{N i}{ }_{N i M O S}}{A M(N i)} \quad \text { Equation (1) }
$$

\subsection{Catalytic testing}

The hydroconversion of pure $n$-hexadecane was carried out in a catalytic test unit with a fixedbed downflow reactor (detailed in SI.1). The catalysts powder was shaped into 0.2-0.35 mm pellets and pre-treated with $\mathrm{H}_{2}\left(4 \mathrm{NL} \mathrm{h}^{-1} \mathrm{~g}^{-1}\right.$ at $4.1 \mathrm{MPa}$ ) at $723 \mathrm{~K}$ over $1 \mathrm{~h}$ (heating at $\left.5 \mathrm{~K} \mathrm{~min}^{-1}\right)$. The tests were conducted at $4.1 \mathrm{MPa}$ of pressure and a $\mathrm{H}_{2}$ to $n-\mathrm{C}_{16}$ molar ratio of 12 . The conversion level was changed by either decreasing the reaction temperature in the 533-548 $\mathrm{K}$ range or increasing the weight hourly space velocity in the $10-100 g_{n c 16} g_{\text {zeolite }} h^{-1}$ range.

The hydroconversion of $n$-hexadecane in presence of $\mathrm{H}_{2} \mathrm{~S}$ and $\mathrm{NH}_{3}$ was carried out in two catalytic test units with fixed-bed downflow reactors. The units differed on the operating space velocities range: $1-4 \mathrm{gnc16}_{\mathrm{nc}} \mathrm{g}_{\text {catalyst }}{ }^{-1} \mathrm{~h}^{-1}$ for the "high-feed" unit and 0.2-1.0 $\mathrm{g}_{\mathrm{nc} 16} \mathrm{~g}_{\text {catalyst }}{ }^{-1} \mathrm{~h}^{-1}$ for the "low-feed" unit. Consequently, the range of reaction temperatures was also different: $613-$ $633 \mathrm{~K}$ and $583-613 \mathrm{~K}$, respectively. Once again, both reaction temperature and space velocities were modified to screen a wide conversion range. All employed procedures were similar. The only difference was on the product separation and analysis, as detailed in SI.1. The shaped catalysts were directly loaded into the reactors. The catalysts were sulphided in situ at $673 \mathrm{~K}$ over $1 \mathrm{~h}$ (heating at $5 \mathrm{~K} \mathrm{~min}^{-1}$ ) using a feedstock with increased $\mathrm{H}_{2} \mathrm{~S}$ partial pressure compared to reaction one (vide SI.1) and a volume hourly space velocity of $4.0 \mathrm{~mL}_{\text {feed }} \mathrm{g}_{\text {catalyst }}{ }^{-1} \mathrm{~h}^{-1}$.

The operating conditions for $n$-hexadecane hydroconversion in presence of $\mathrm{H}_{2} \mathrm{~S}$ and $\mathrm{NH}_{3}$ are summarized in Table 1. The catalytic tests were carried out in presence of $11 \mathrm{kPa}$ of $\mathrm{H}_{2} \mathrm{~S}$ (through decomposition of dimethyl disulphide) and $3.8 \mathrm{kPa}$ of $\mathrm{NH}_{3}$ (through decomposition of aniline), at $4.1 \mathrm{MPa}$ of total pressure and a molar $\mathrm{H}_{2}$ to $\mathrm{n}-\mathrm{C}_{16}$ ratio of 12 . These operating conditions are in line with the industrial ones (Table 1). The only exception is the total pressure which was kept lower than the industrial one due to safety reasons. 
Table 1: Comparison of the operating conditions used in this work and in industrial

\begin{tabular}{lcccccc}
\cline { 2 - 7 } & $\begin{array}{c}\text { Pressure } \\
(\mathrm{MPa})\end{array}$ & $\begin{array}{c}\text { Temperature } \\
(\mathrm{K})\end{array}$ & $\begin{array}{c}\mathrm{H}_{2} / \mathrm{HC} \\
\left(\mathrm{m}^{3} / \mathrm{m}^{3}\right)\end{array}$ & $\begin{array}{c}\text { LHSV } \\
\left(\mathrm{h}^{-1}\right)\end{array}$ & $\begin{array}{c}\text { Sulphur } \\
(\text { wt. ppm })\end{array}$ & $\begin{array}{c}\text { Nitrogen } \\
(\text { wt. ppm })\end{array}$ \\
\hline This work & 4.1 & $593-633$ & 1000 & $0.2-4$ & 10200 & 750 \\
Industrial HCK ${ }^{31}$ & $10-20$ & $623-703$ & $800-2000$ & $0.2-2$ & $1000-20000$ & $300-2000$ \\
\hline
\end{tabular}

3 In the case of $n$-paraffins hydroconversion, it has been repeatedly confirmed that the overall 4 reaction follows a first-order kinetics in the paraffin concentration ${ }^{13,32,33}$. The catalytic activity 5 was thus calculated as the apparent kinetic constant for first-order consumption of $n$ 6 hexadecane normalized per catalyst mass. The selectivity of a given product was calculated as 7 the amount of carbon atoms from that product divided by total amount of carbon atoms in the 8 products. Yield was calculated as a product of conversion and selectivity.

\section{Academic case study: Pt/HUSY in pure $n$-hexadecane} hydroconversion

As referred in the Introduction, the effect of metal-acid sites ratio in Pt/HUSY has been extensively study in the hydroconversion of $n$-alkanes. For the catalysts employed in this study, this effect has been even quantified in a previous work, establishing the well-balanced character of catalysts holding 0.4 and 0.7 wt. $\%$ of platinum ${ }^{13}$. Hence, the latter catalyst was selected as the well-balanced Pt/HUSY catalyst to be tested at similar conditions to the NiMo-based ones in this study. It shall be noted that the preceding hydroconversion tests ${ }^{13}$ were performed at a total pressure of $1.1 \mathrm{MPa}$ whereas the tests herein were carried out at $4.1 \mathrm{MPa}$, to better reproduce industrial conditions (vide previous section).

\subsection{Physico-chemical properties of the materials}

Table 2 summarize the main features of both the HUSY zeolite and the Pt/HUSY catalyst. Most relevant for the purpose of this work are the concentrations of the active sites in the $\mathrm{Pt} / \mathrm{HUSY}$ catalyst. The concentration of Brønsted acid sites amounted to $820 \mu \mathrm{mol} \mathrm{g}{ }^{-1}$, based on the concentration of $\mathrm{Al}^{\mathrm{IV}}$ atoms $\left(\mathrm{n}_{\mathrm{Al}}\right)^{27}$. The metal dispersion was ca. $52 \%$, resulting in a metal to acid sites molar ratio of 0.023 . Concerning the location, Pt nanoparticles have been observed to be mainly located in the micropores of HUSY zeolite ${ }^{30}$.

Table 2: Physico-chemical, textural and structural characteristics of HUSY zeolite and corresponding Pt-containing bifunctional catalyst ${ }^{13,27}$.

\begin{tabular}{|c|c|c|c|c|c|c|c|}
\hline \multicolumn{5}{|c|}{ HUSY } & \multicolumn{3}{|c|}{ Pt/HUSY } \\
\hline $\begin{array}{l}V_{\text {micro }} \\
\left(\mathrm{cm}^{3} \mathrm{~g}^{-1}\right)\end{array}$ & $\begin{array}{c}S_{\text {ext }} \\
\left(m^{2} g^{-1}\right)\end{array}$ & $(\mathrm{Si} / \mathrm{Al})_{\text {global }}$ & $(\mathrm{Si} / \mathrm{Al})_{\text {framework }}$ & $\begin{array}{c}\mathrm{n}_{\mathrm{Al}} \\
\left(\mu \mathrm{mol} \mathrm{\textrm {g } ^ { - 1 }}\right)\end{array}$ & $\begin{array}{l}\text { Pt loading } \\
\text { (wt.\%) }\end{array}$ & $\begin{array}{c}\text { Pt dispersion } \\
\text { (\%) }\end{array}$ & $\begin{array}{c}\mathrm{n}_{\mathrm{Pt}} / \mathrm{n}_{\mathrm{Al}} \\
\left(\mathrm{mol} \mathrm{mol}^{-1}\right)\end{array}$ \\
\hline 0.33 & 101 & 16.7 & 18.4 & 820 & 0.7 & 52 & 0.023 \\
\hline
\end{tabular}




\section{$2 \quad 3.2$ Catalytic behaviour}

3 Figure 1a) depicts the evolution of $n$-hexadecane conversion in terms of $1^{\text {st }}$-order kinetics as 4 function of contact time. A very good fit to the rate law can be observed, confirming once again 5 the results in literature for $n$-paraffins hydroconversion ${ }^{13,32,33}$. This allowed the calculation of 6 both the catalyst activity and turnover frequency at the different temperatures (Table SI2). At $7548 \mathrm{~K}$, for instance, the values were $61 \mathrm{\mu mol} \mathrm{g}^{-1} \mathrm{~s}^{-1}$ and $75 \cdot 10^{-3} \mathrm{~s}^{-1}$, respectively. The apparent 8 activation energy was ca. $188 \mathrm{~kJ} \mathrm{~mol}^{-1}$, in agreement with previous values reported (150-190 kJ $9 \mathrm{~mol}^{-1}$ ) for pure $n$-hexadecane hydroconversion on $\mathrm{Pt} /$ /zeolite catalyst $^{13,34}$.

The yield of hexadecane isomers as a function of $n$-hexadecane conversion is represented in Figure 1b). A unique curve, regardless of the reaction temperature, was obtained, as expected for a well-balanced catalyst ${ }^{28,35,36}$. The maximal isomer yield was about $50 \%$.
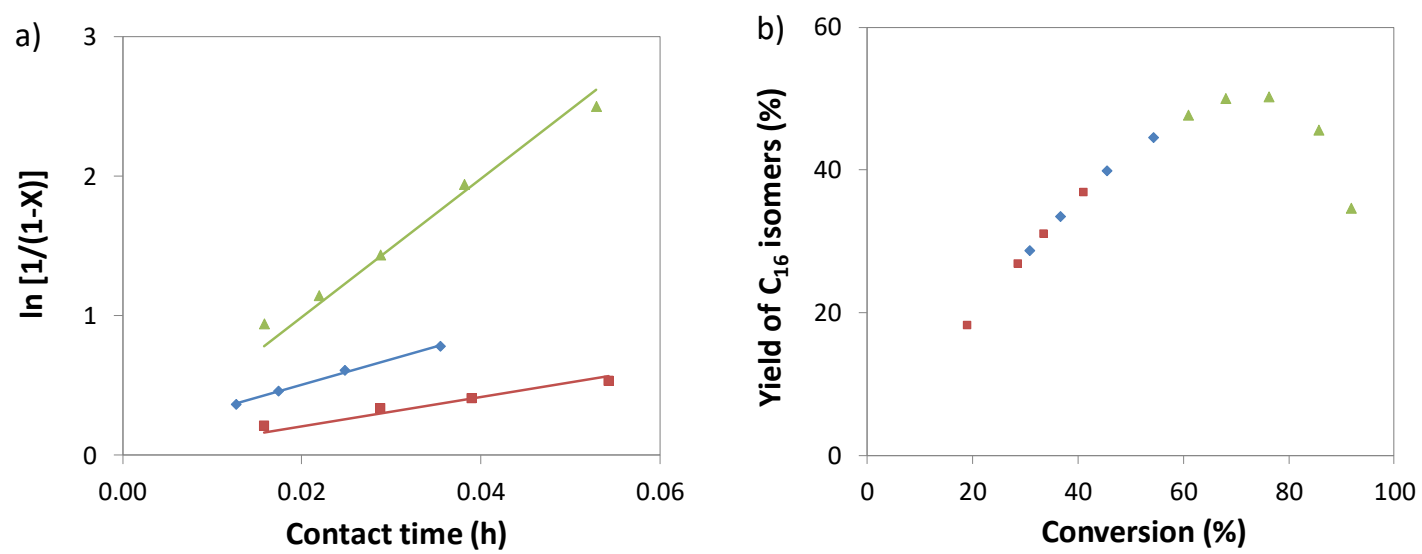

Figure 1: a) $1^{\text {st }}$-order plot of $n$-hexadecane conversion $(X)$ as function of contact time and $b$ ) yield of $\mathrm{C}_{16}$ isomers as function of conversion, over $\mathrm{Pt} / \mathrm{HUSY}$ catalyst. Reaction temperatures: $528(\square), 538(\diamond)$, and $548 \mathrm{~K}(\Delta)$. Symbols stand for experimental data and lines for the corresponding linear regression.

\section{Industrial case study: $\mathrm{NiMoS} /\left(\mathrm{Al}_{2} \mathrm{O}_{3}+\mathrm{HUSY}\right)$ in $n$-hexadecane hydroconversion in presence of $\mathrm{H}_{2} \mathrm{~S}$ and $\mathrm{NH}_{3}$}

Conversely to $\mathrm{Pt} /$ zeolite catalysts, the impact of the balance between the two catalytic functions on the catalyst performances has been seldom studied over NiMoS-based shaped catalysts. To investigate it, catalysts with different molybdenum loadings (from 9 to $17 \mathrm{wt} . \%$ ) were firstly synthesized and evaluated for $n$-hexadecane hydroconversion. Aiming at somewhat mimicking the industrial reaction medium, both $\mathrm{H}_{2} \mathrm{~S}$ and $\mathrm{NH}_{3}$ were present in this case. No noticeable evolution of the activity with Mo loading and only a minor evolution on the maximal $\mathrm{C}_{16}$ isomer 
1 yield were observed(vide SI.4 for full results). Hence, a NiMoS/( $\left.\mathrm{Al}_{2} \mathrm{O}_{3}+\mathrm{HUSY}\right)$ catalyst with 2 intermediate Mo content (12 wt.\%) was selected to compare against the well-balanced $3 \mathrm{Pt} / \mathrm{HUSY}$.

4 The comprehensive characterization results and discussion of all $\mathrm{NiMoS} /\left(\mathrm{Al}_{2} \mathrm{O}_{3}+\mathrm{HUSY}\right)$ 5 catalysts can be found in SI (section SI.3). The focus herein has been put on the $612 \mathrm{NiMo} /\left(\mathrm{Al}_{2} \mathrm{O}_{3}+\mathrm{HUSY}\right)$ sample.

\section{$7 \quad 4.1$ Physico-chemical properties of the materials}

8 The zeolitic trilobed extrudates comprised $83.5 \%$ of $\mathrm{y}$-alumina and $16.5 \%$ of HUSY zeolite, 9 based on the amount of silicon detected in shaped samples (Erreur! Source du renvoi introuvable.). In a previous study, the characterization of the shaped sample hinted at a full preservation of the zeolite properties in the extrudates, in particular the zeolite porosity and Brønsted acidity ${ }^{28}$. The concentration of protonic $\mathrm{Al}^{\mathrm{IV}}$ sites in the extrudates can be thus directly estimated via that of the parent zeolite, taking into account the zeolite fraction in the shaped support. The concentration of Brønsted acid sites is thus expected to be around $135 \mu \mathrm{mol}$ gsupport $^{-1}$.

Table 3: Physico-chemical, textural and structural characteristics of HUSY shaped support ${ }^{28}$ and $\mathrm{NiMoS} /\left(\mathrm{Al}_{2} \mathrm{O}_{3}+\mathrm{HUSY}\right)$.

\begin{tabular}{|c|c|c|c|c|c|}
\hline \multicolumn{3}{|c|}{$\mathrm{Al}_{2} \mathrm{O}_{3}+\mathrm{HUSY}$ extrudates } & \multicolumn{3}{|c|}{$\mathrm{NiMoS} /\left(\mathrm{Al}_{2} \mathrm{O}_{3}+\mathrm{HUSY}\right)$} \\
\hline $\begin{array}{c}\text { Si } \\
\text { (wt.\%) }\end{array}$ & $\begin{array}{l}\text { Zeolite } \\
\text { (wt.\%) }\end{array}$ & $\begin{array}{c}\mathrm{n}_{\mathrm{Al}} \\
\left(\mu \mathrm{mol} \mathrm{g}_{\text {support }}{ }^{-1}\right)\end{array}$ & $\begin{array}{l}\text { Mo loading } \\
\text { (wt.\%) }\end{array}$ & $\begin{array}{c}\mathrm{n}_{\text {NiMos }} / \mathrm{n}_{\mathrm{Mo}} \\
\text { (mol.\%) }\end{array}$ & $\begin{array}{c}\mathrm{n}_{\text {NiMos }} / \mathbf{n}_{\mathrm{Al}} \\
\left(\mathrm{mol} \mathrm{mol}^{-1}\right)\end{array}$ \\
\hline 7.3 & 16.5 & 135 & 12.0 & 16 & 2.9 \\
\hline
\end{tabular}

18

The Ni-decorated $\mathrm{MoS}_{2}$ slabs had average length of $3.2 \mathrm{~nm}$ (Table SI5). The corresponding $\mathrm{Ni} /$ Mo molar ratio was about 0.28 (Table SI5) and so somewhat lower than the global Ni/Mo molar ratio of 0.40 (Table SI3). To quantify the active sites for $\mathrm{HDH}$ reactions, i.e. the $\mathrm{MoS}_{2}$ sites promoted with $\mathrm{Ni}$ (so-called mixed sites) ${ }^{37,38}$, a methodology based on X-ray photoelectron spectroscopy ${ }^{29}$ was employed. Accordingly, the concentration of NiMoS sites in the catalyst $\left(\mathrm{n}_{\text {NiMoS }}\right)$ was about $0.28 \mathrm{mmol} \mathrm{g}^{-1}$. The corresponding NiMoS sites to $\mathrm{Al}^{\mathrm{IV}}$ sites molar ratio was 2.9 (Table 3). Based on NiMoS sites concentration, the amount of Mo incorporated in the NiMoS site could be assessed. It corresponded to ca. $15 \%$ of the overall Mo deposed on the catalyst. Such low values were somewhat expected as only the Mo-edge sites of the slabs are available to be promoted by nickel.

An uniform distribution of the metals along the extrudate diameter both before, as previously reported as well ${ }^{29}$, and after sulfidation (Figure Sl1a) was observed, validating the protocol employed to generate the NiMoS active phase. Concerning the location of the metals in the 
support, both nickel and molybdenum were preferentially located in the alumina (Figure SI1b).

2 Nevertheless, whereas only $1 \%$ of all Mo was deposed in the zeolite, that was $7 \%$ in the case of

$3 \mathrm{Ni}$. Such distribution is in line with the electrostatic interactions between the metal species and

4 the support components in solution (vide SI.3 for full discussion). As, for slabs of $3.2 \mathrm{~nm}, \mathrm{Ni} / \mathrm{Mo}$

5 molar ratios above 0.5 no longer result in the decoration of Mo atoms leading instead to the

6 decoration of $\mathrm{Ni}$ atoms (forming thus $\mathrm{NiS}_{\mathrm{x}}$ sites) ${ }^{37}$, most of the nickel in the zeolite shall be

7 under rather inactive forms. In practice, virtually all the $\mathrm{HDH}$ function was located in the alumina.

\section{$8 \quad 4.2$ Catalytic behaviour}

9 The evolution of the apparent kinetic constant for $n-C_{16}$ consumption (which is equivalent to the 10 catalytic activity per catalyst mass according to our definition of the latter) with temperature was represented by an Arrhenius' plot in Figure 2a). An excellent fit of experimental data to Arrhenius' equation was observed. The apparent activation energy estimated amounted to 286 $\mathrm{kJ} \mathrm{mol}^{-1}$. This contrasts with the activation energy of $188 \mathrm{~kJ} \mathrm{~mol}^{-1}$ over Pt/HUSY and the typical range reported in literature (150-190 $\left.\mathrm{kJ} \mathrm{mol}^{-1}\right)^{13,34}$. This difference can be tentatively explained by the presence of $\mathrm{NH}_{3}$, because ammonia adsorbs on the acid sites of the HUSY zeolite and its coverage decreases with temperature (chemisorption being exothermic). As a consequence the amount of protonic sites available for catalysis increases when the temperature is increased. As a matter of fact, literature on $n-\mathrm{C}_{16}$ hydroconversion reported an increase in the apparent activation energy, in presence of $\mathrm{NH}_{3}$, of about $100 \mathrm{~kJ} \mathrm{~mol}^{-1}{ }^{34}$. In cyclohexane hydroisomerization, we had also observed an increase in activation energy of about $90 \mathrm{~kJ} \mathrm{~mol}^{-1}$ 29. In both studies, this increment has been attributed to the contribution of $\mathrm{NH}_{3}$ desorption enthalpy to the apparent activation energy.
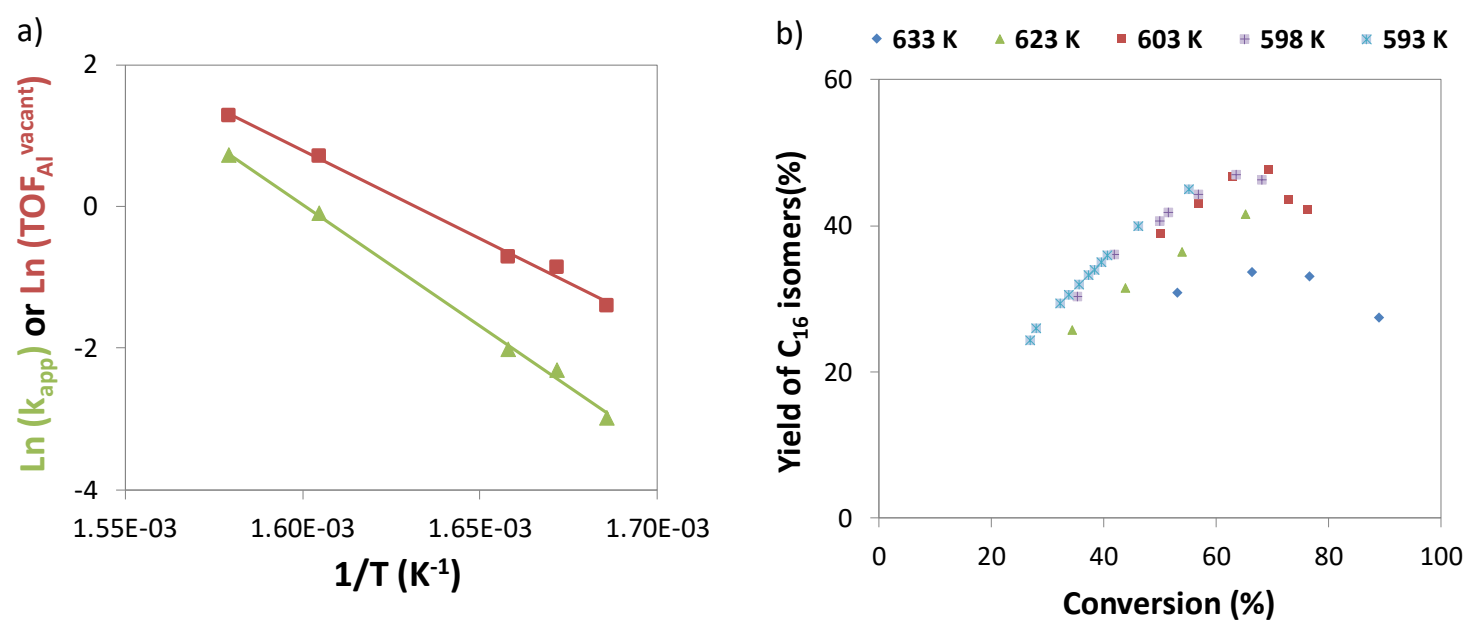

Figure 2: a) Arrhenius' plot for catalytic activity $(\Delta)$ and turnover frequency per available protonic site ( $\square)$. Symbols stand for experimental data and lines for model fitted Arrhenius' equation. Units of $k_{\text {app }}$ : $\mu \mathrm{mol} g_{\text {zeolite }}{ }^{-1} \mathrm{~s}^{-1}$. Units of TOF ${ }_{\mathrm{Al}}^{\text {vacant }}: \mathrm{s}^{-1}$ (molar basis). b) Yield of feed isomers as function of conversion at different reaction temperatures. Catalyst: $\mathrm{NiMoS} /\left(\mathrm{Al}_{2} \mathrm{O}_{3}+\mathrm{HUSY}\right)$. 
1 Figure $2 b$ ) depicts the evolution of $\mathrm{C}_{16}$ isomers yield with conversion obtained at different reaction temperatures for $\mathrm{NiMoS} /\left(\mathrm{Al}_{2} \mathrm{O}_{3}+\mathrm{HUSY}\right)$ catalyst. The yield of feed isomers at a given conversion remarkably increased with decreasing temperatures. From 633 to $623 \mathrm{~K}$, the $\mathrm{C}_{16}$ isomer yield at $60 \%$ of conversion increased from $34 \%$ to $42 \%$. Further increase to $47 \%$ was achieved by decreasing the temperature to $603 \mathrm{~K}$. From 603 to $598 \mathrm{~K}$, the differences between $\mathrm{C}_{16}$ isomer yield curves were more subtle. The nearly overlapping curves at 598 and $593 \mathrm{~K}$ pointed as well to a greater effect at higher temperatures.

8 A remarkable impact of temperature on $\mathrm{C}_{16}$ isomer yield was hence evident over $9 \mathrm{NiMoS} /\left(\mathrm{Al}_{2} \mathrm{O}_{3}+\mathrm{HUSY}\right)$ catalyst. This kind of temperature effect has been explained in hydrocracking by the gap in the activation energies of the reactions occurring in the two functions of the catalyst: the apparent activation energy of the HDH reactions is lower than that of the acid-catalysed reactions and then the latter are more temperature-dependent ${ }^{35}$. Hence, as temperature decreases, the kinetic constant ratio of $\mathrm{HDH}$ reactions to acid-catalysed reactions will increase. This will lead to a better balance of the acid function by the HDH function. However, in the case of an excess of HDH to acid activity (i.e. in sufficiently wellbalanced catalysts), the kinetic constants ratio will have no practical effect on the metal-acid balance: the catalysts would still be well-balanced, just the excess of HDH activity would be smaller. In fact, no temperature dependence was found over the Pt/HUSY herein (Figure 1b). The occurrence of unique curve for feed isomer yield as function of conversion has been vastly reported in the literature for well-balanced catalysts over relative wide range of operating conditions ${ }^{28,35,36}$. In particular, a similar feed isomers yield curve can be obtained within a temperature span of $65 \mathrm{~K}^{36}$.

In summary, the noteworthy decrease in feed isomer yield with increasing temperature might have been due to the change in the kinetic constants ratios with temperature, but other causes cannot be ruled out. Particularly, in presence of analogous partial pressures of ammonia, the number of available Brønsted sites for reaction (i.e. non-inhibited by $\mathrm{NH}_{3}$ ) has been determined to be quite small (below $2 \%$ ) and dependent on the temperature at stake, due to $\mathrm{NH}_{3}$ desorption with increasing temperatures ${ }^{29}$. Consequently, the effective $\mathrm{HDH}$ to protonic sites ratio is also temperature-dependent in presence of ammonia.

\section{Impact of $\mathrm{NH}_{3}$ adsorption on NiMoS-to-acid sites ratio}

The concentration of vacant protonic sites ( $\mathrm{n}_{\mathrm{Al}}^{\text {vacant }}$ ) at a given temperature and $\mathrm{NH}_{3}$ partial pressure corresponds to the fraction of vacant sites at that temperature and pressure times the overall concentration of sites (i.e. $\mathrm{n}_{\mathrm{Al}}$ ) - Eq. (2). The fraction of vacant sites has been previously determined for similar temperatures and analogous ammonia partial pressures ${ }^{29}$. The data and calculation details can be found in SI.5. It shall be noted that the goal is to get hold of the order 
1 it. As the estimations are based on Arrhenius' equation, which contains an exponential term, the 2 values themselves shall be taken cautiously.

$$
n_{A l}^{\text {vacant }}\left(T, P_{N_{3}}\right)=\Psi_{V}\left(T, P_{N H_{3}}\right) \times n_{A l}
$$

3 In order to evaluate the effect of temperature in presence of ammonia, the estimated 4 concentration of vacant (i.e. non-inhibited) Brønsted acid sites was plotted as a function of 5 temperature (Figure 3a). The concentration of protonic sites vacant for reaction almost triples 6 within the range of studied temperatures. The concentrations at stake correspond to the 7 inhibition of 99.4 to $99.8 \%$ of the $820 \mu \mathrm{mol}$ g $_{\text {zeolite }}{ }^{-1}$ Brønsted sites in the HUSY zeolite. It is 8 worth mentioning that, as this corresponds to nearly saturation of the protonic sites, these 9 results (and the corresponding conclusions) are relative insensitive to ammonia pressure 10 changes within comparable orders of magnitude ${ }^{29}$.

11 To determine the ratio of the number of available NiMoS sites to the number of available 12 Brønsted sites ( $\mathrm{n}_{\text {Nimos }} / \mathrm{n}_{\mathrm{Al}}{ }^{\text {vacant }}$ ) as a function of temperature, the effect of temperature on the 13 available NiMoS sites should also be investigated. Although NiMoS sites are known to be Lewis 14 acid sites, its acidity is much lower than that of a zeolite, particularly the HUSY one employed. 15 Regarding $\mathrm{H}_{2} \mathrm{~S}$, it is known to inhibited $\mathrm{HDH}$ molybdenum mixed sites ${ }^{38-42}$. Nevertheless, $\mathrm{H}_{2} \mathrm{~S}$ 16 inhibiting effect on these sites is expected to be several orders of magnitude weaker than that of $17 \mathrm{NH}_{3}$ on Brønsted sites ${ }^{43}$. For instance, under comparable operating conditions, a 4-fold 18 reduction in the hydrogenating activity of NiMoS catalysts has been reported, as compared to $\mathrm{H}_{2} \mathrm{~S}$-free reaction medium ${ }^{41}$. Hence, even though both $\mathrm{NH}_{3}$ and $\mathrm{H}_{2} \mathrm{~S}$ will also inhibit the $\mathrm{HDH}$ 20 sites in the NiMoS/(HUSY $\left.+\mathrm{Al}_{2} \mathrm{O}_{3}\right)$ catalyst, the fraction of non-inhibited active sites should be considerably higher than that of protonic ones. Therefore, for the purpose of this study, the concentration of available NiMoS sites was hence assumed to be independent of the operating conditions and similar to the values of nNimos previously obtained (Table SI5).

Figure $3 b$ depicts the estimated evolution of $n_{\text {Nimos }} / n_{A l}{ }^{\text {vacant }}$ with temperature. Decreasing the reaction temperature can substantially augment the $\mathrm{n}_{\text {NiMos }} / \mathrm{n}_{\mathrm{Al}}{ }^{\text {vacant }}$, by means of the decreasing number of vacant Brønsted sites due to greater $\mathrm{NH}_{3}$ adsorption. In particular, from to 633 to $593 \mathrm{~K}$, the molar sites ratio almost tripled. It is worth noting that this represents a greater growth in the $\mathrm{n}_{\text {NiMos }} / \mathrm{n}_{\mathrm{Al}}$ vacant than that obtained by increasing the Mo content from 9 to $17 \%$. 

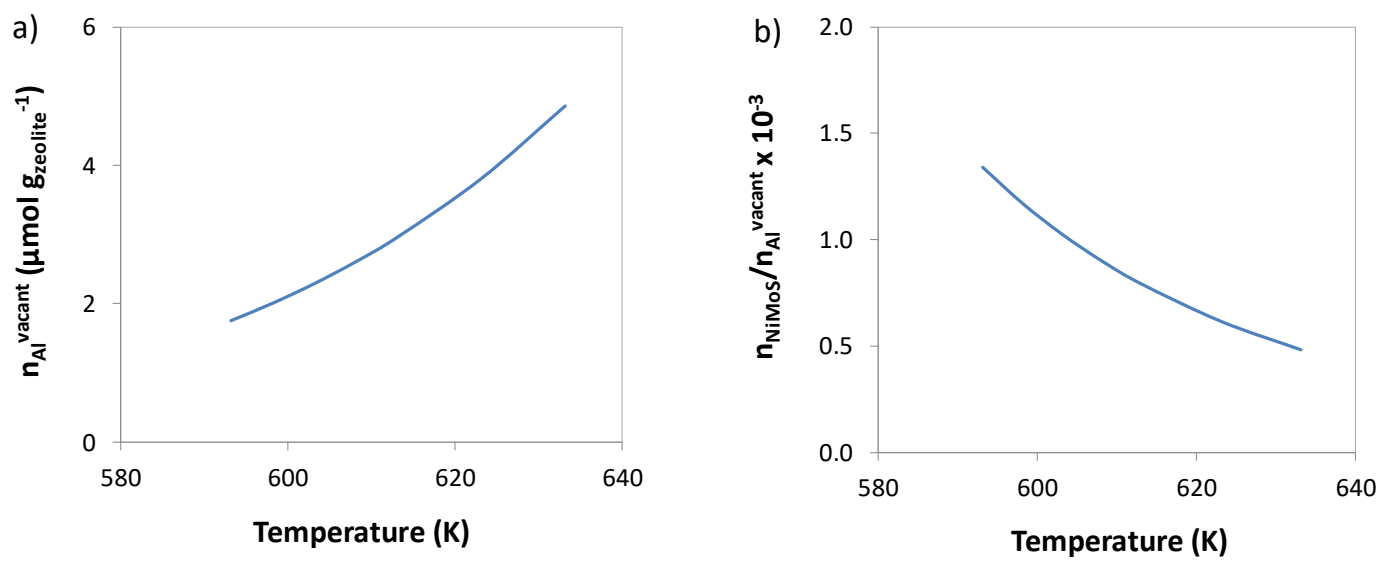

Figure 3: Estimated evolution of a) the concentration of vacant acid sites in the HUSY zeolite and $b$ ) the molar ratio of NiMoS to vacant Brønsted sites with temperature, under reaction conditions.

The estimation of the concentration of vacant sites $\left(n_{A l}{ }^{\text {vacant }}\right)$ enabled the calculation of the turnover frequency over the Brønsted acid sites $\left(\mathrm{TOF}_{\mathrm{Al}}{ }^{\text {vacant }}\right)$. When compared to the evolution of catalytic activity with temperature (Figure 2a), a clear lower slope is observed for the turnover frequency. The apparent activation energy was estimated in $187 \mathrm{~kJ} \mathrm{~mol}^{-1}$, in the typical range for the hydroconversion of $n$-hexadecane, whereas that for catalytic activity amounted to $286 \mathrm{~kJ}$ $\mathrm{mol}^{-1}$. The abovementioned hypothesis on the contribution of $\mathrm{NH}_{3}$ desorption enthalpy to the apparent activation energy in the $\mathrm{NiMoS} /\left(\mathrm{HUSY}+\mathrm{Al}_{2} \mathrm{O}_{3}\right)$ catalyst was, hence, further supported, along with the importance of ammonia inhibition of the Brønsted acid sites.

In view of the previous observation, the superior $C_{16}$ isomers yields reached at lower reaction temperatures (Figure $2 b$ ) can be tentatively explained by the larger $n_{\text {NiMoS }} / n_{A l}$ vacant ratios. As the temperature decreased, the gain in isomer yield diminished and overlapped curves were even observed at the lowest temperatures. This pointed towards an approach to the plateau of maximal $\mathrm{C}_{16}$ isomer yield for temperatures about $593 \mathrm{~K}$, because, even if the metal to acid sites ratio continuously increased (Figure $3 b$ ), the isomer yield became constant. In other words, the maximal $\mathrm{C}_{16}$ isomers yields observed at such temperatures most likely correspond to the performance of a well-balanced catalyst. In such case, the hydrogenation/dehydrogenation reactions are much faster than the acid-catalyzed ones, limiting consecutive reactions and, hence, maximizing the feed isomers yield ${ }^{13,44}$.

In summary, the temperature effect on the catalyst hydroisomerisation selectivity observed can be explained by both the improvement of balance between the two catalytic functions, due to either a higher kinetic constants ratio of $\mathrm{HDH}$ reactions to acid-catalysed ones or a higher metal to acid sites ratio. Most likely, the two phenomena took place simultaneously explaining hence the considerable increase in the maximal $C_{16}$ isomers yield for temperature intervals as narrow as $5 \mathrm{~K}$. Conversely, the observed improvement in the balance of acid function by HDH function implied that catalysts were far from the optimal balance at the initial operating conditions (i.e. high temperatures). Hence, the insensitivity of the catalytic performance to increased 
molybdenum loadings, observed in the preliminary tests (vide SI.4), implies a relatively constant the metal-acid balance regardless of the Mo loading. In other words, the $\mathrm{HDH}$ activity remained similar although the active metal content was doubled (from $9 \%$ to $17 \%$ ).

\section{$4 \quad 5 \quad$ Academic vs. industrial case studies}

\section{$5 \quad 5.1$ Activity}

6 To disregard the simple effect of the lower zeolite content in the NiMoS/( $\left.\mathrm{Al}_{2} \mathrm{O}_{3}+\mathrm{HUSY}\right)$ catalyst,

7 the activity was normalized per zeolite mass. Due different temperature ranges, the catalytic 8 activity was compared through an Arrhenius's plot (Figure 4a). Pt/HUSY exhibited a significantly 9 higher catalytic activity than $\mathrm{NiMoS} /\left(\mathrm{Al}_{2} \mathrm{O}_{3}+\mathrm{HUSY}\right)$ for a much lower reaction temperature. In 10 order to compare directly the catalysts activity, the Arrhenius' equations of NiMoS-catalysts were extrapolated to the same level of activity of Pt-catalysts. In doing so, it became noticeable that the reaction temperature would have to be increased by ca. $125 \mathrm{~K}$ in order for NiMoS/( $\mathrm{Al}_{2} \mathrm{O}_{3}+\mathrm{HUSY}$ ) catalyst to attain the activity level (zeolite mass) of Pt/HUSY one ${ }^{2}$.

a)

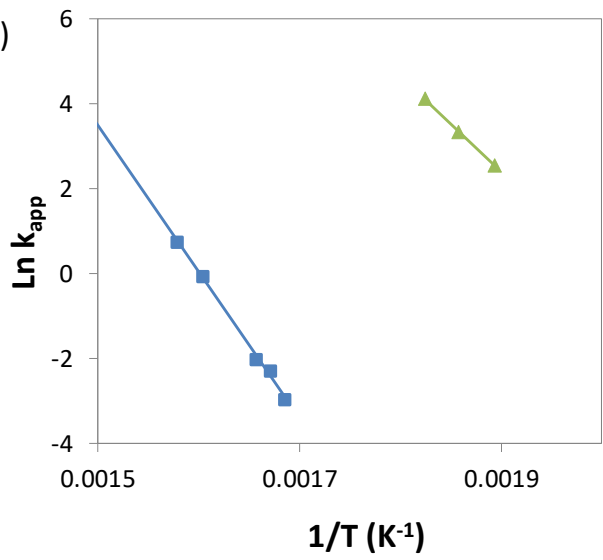

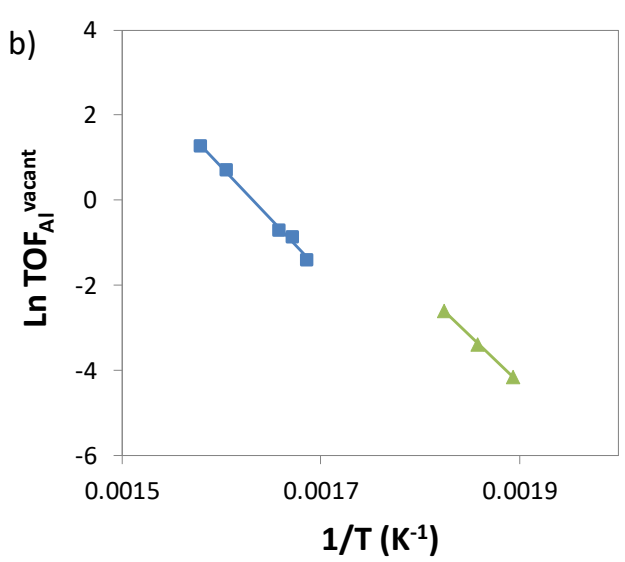

Figure 4: Arrhenius's plot for a) catalytic activity and b) turnover frequency per vacant protonic site over Pt/HUSY $(\Delta)$ and $\mathrm{NiMoS} /\left(\mathrm{Al}_{2} \mathrm{O}_{3}+\mathrm{HUSY}\right)(\square)$ catalysts. Symbols stand for experimental data and lines for regression of the Arrhenius equation. Units of $k_{\text {app }}: \mu \mathrm{mol} g_{\text {zeolite }}{ }^{-1} \mathrm{~s}^{-1}$. Units of TOF $_{A l}^{\text {vacant: }} \mathrm{s}^{-1}$ (molar basis).

\subsection{Turnover frequency over available protonic sites}

The evolution of the turnover frequency over the available protonic sites with temperature is shown in Figure 4b). It is should be borne in mind that, for Pt/HUSY, the concentration of Brønsted sites in the catalyst corresponded to that of $\mathrm{Al}^{\mathrm{IV}}$ species, as no $\mathrm{NH}_{3}$ was fed in this

\footnotetext{
${ }^{2}$ Due to the large difference in the activation energies, the comparison of catalytic activities is very temperature-dependent. For instance, when considering $548 \mathrm{~K}$ (i.e. the lowest temperature at which $\mathrm{Pt} / \mathrm{HUSY}$ was tested), the activity ratio amounts to $3 \cdot 10^{6}$ in favor of $\mathrm{Pt} / \mathrm{HUSY}$ catalyst. When considering $633 \mathrm{~K}$ (i.e. the highest temperature at which $\mathrm{NiMoS} /\left(\mathrm{HUSY}+\mathrm{Al}_{2} \mathrm{O}_{3}\right)$ was tested), the activity ratio decreases to $7 \cdot 10^{3}$. Hence, reaction temperature was preferred to compare catalyst activity.
} 
case. In the case of NiMoS/ $\left(\mathrm{Al}_{2} \mathrm{O}_{3}+\mathrm{HUSY}\right)$, in order to account for the inhibition of the acid sites by $\mathrm{NH}_{3}$, the concentration of vacant protonic sites (as estimated in Section 4.2) was employed.

$3 \mathrm{NiMoS} /\left(\mathrm{Al}_{2} \mathrm{O}_{3}+\mathrm{HUSY}\right)$ revealed superior $\mathrm{TOF}_{\mathrm{Al}}$ vacant than $\mathrm{Pt} / \mathrm{HUSY}$ but it was also tested at 4 higher temperatures. Comparing both catalysts at similar temperatures, the turnover 5 frequencies over $\mathrm{NiMoS} /\left(\mathrm{HUSY}+\mathrm{Al}_{2} \mathrm{O}_{3}\right)$ were of comparable order of magnitude to those over $6 \mathrm{Pt} / \mathrm{HUSY}$ catalysts. Especially, when comparing with very large gap between catalytic activities 7 (Figure 4a). Although precaution is advisable as data was not (and cannot be) obtained at 8 similar temperatures, the results seemingly pointed out a comparable intrinsic activity of 9 available Brønsted site regardless of the differences in catalysts composition.

Taking into account the concentration of vacant acid sites, the apparent activation energies were found to be remarkably similar for Pt/HUSY (188 kJ/mol) and NiMoS/( $\left.\mathrm{Al}_{2} \mathrm{O}_{3}+\mathrm{HUSY}\right)(187$ $\mathrm{kJ} / \mathrm{mol}$ ) catalysts. The activation energies seemed hence to be intrinsic to the zeolite function and independent of the $\mathrm{HDH}$ function. These results pointed to the rate-determining character of the acid-catalyzed reactions in the conversion of $n$-hexadecane, in agreement with the wellbalanced character of $\mathrm{Pt} / \mathrm{HUSY}$. For NiMoS/ $\left(\mathrm{Al}_{2} \mathrm{O}_{3}+\mathrm{HUSY}\right)$, the similarities to $\mathrm{Pt} / \mathrm{HUSY}$ strongly supported that the plateau in terms of activity per protonic site was also reached with the NiMoS-acid sites ratios at stake. As discussed above, for NiMoS $/\left(\mathrm{Al}_{2} \mathrm{O}_{3}+\mathrm{HUSY}\right)$, the apparent activation energy corresponds to the apparent overall activation energy (as calculated by the Arrhenius' equation for catalytic activity) subtracted by enthalpy of $\mathrm{NH}_{3}$ desorption from the acid sites.

\subsection{Selectivity towards isomerization}

Figure 5 provides the evolution of $\mathrm{C}_{16}$ isomers yield as a function of $n$-hexadecane conversion for both catalysts. Over NiMoS/( $\left.\mathrm{Al}_{2} \mathrm{O}_{3}+\mathrm{HUSY}\right)$, the evolution of $\mathrm{C}_{16}$ isomers yield was influenced by the reaction temperature (593-633 K), as previously discussed, whereas a unique tendency for isomer yield was obtained over $\mathrm{Pt} / \mathrm{HUSY}$ catalyst regardless of the temperature at stake (528-548 K). The comparison between catalysts performance is thus temperature-dependent. At $633 \mathrm{~K}$, the maximal $\mathrm{C}_{16}$ isomers yield reachable over $\mathrm{NiMoS} /\left(\mathrm{Al}_{2} \mathrm{O}_{3}+\mathrm{HUSY}\right)$ catalyst was considerably lower than the one obtained over Pt/HUSY catalyst. However, as temperature was decreased over the NiMoS-catalyst, the isomers yield increased for a given conversion (see Figure $2 \mathrm{~b}$ ). In fact, the evolution of $\mathrm{C}_{16}$ isomers yield with conversion at the lowest investigated temperature $(593 \mathrm{~K})$ over $\mathrm{NiMoS} /\left(\mathrm{Al}_{2} \mathrm{O}_{3}+\mathrm{HUSY}\right)$ was remarkably similar to that of $\mathrm{Pt} / \mathrm{HUSY}$ (even though the maximum of $\mathrm{C}_{16}$ isomers yield curve could not be measured over this NiMoScatalyst as the maximum achievable conversion decreased with decreasing temperature). The catalysts revealed hence the same selectivity in feed isomers for a temperature sufficiently low over the NiMoS/( $\left.\mathrm{Al}_{2} \mathrm{O}_{3}+\mathrm{HUSY}\right)$, notwithstanding the reaction temperature gap of up to $65 \mathrm{~K}$. 


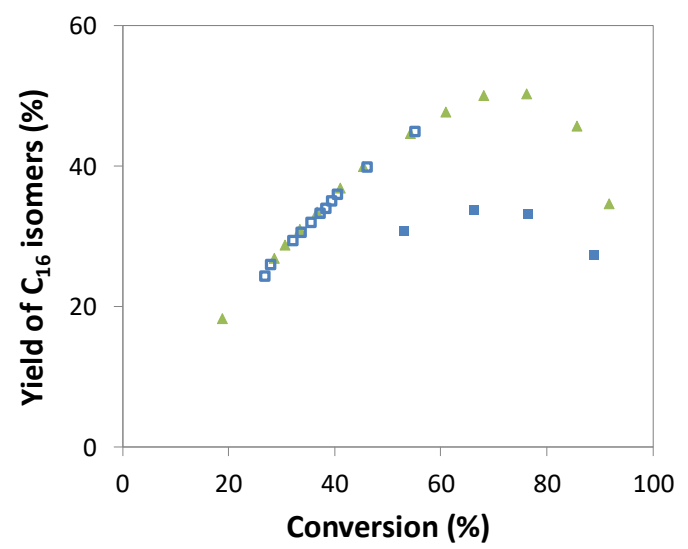

Figure 5: Yield of $\mathrm{C}_{16}$ isomers as a function of conversion over $\mathrm{Pt} / \mathrm{HUSY}$ at 528-548 $\mathrm{K}(\mathrm{A})$ and $\mathrm{NiMoS} /\left(\mathrm{Al}_{2} \mathrm{O}_{3}+\mathrm{HUSY}\right)$ catalyst at $633(\square)$ and $593 \mathrm{~K}(\square)$.

In Section 4.2, this temperature effect was associated with an improvement of the metal-acid balance. The performance of $\mathrm{NiMoS} /\left(\mathrm{HUSY}+\mathrm{Al}_{2} \mathrm{O}_{3}\right)$ catalyst at the lowest temperatures corresponded hence to that of a well-balanced catalyst. The similar results to Pt/HUSY, which was known to be well-balanced, reinforced that conclusion. In other words, when well-balanced, $\mathrm{Pt} / \mathrm{HUSY}$ and $\mathrm{NiMoS} /\left(\mathrm{HUSY}+\mathrm{Al}_{2} \mathrm{O}_{3}\right)$ catalysts apparently hold the same intrinsic performance, in spite of the differences in terms of catalyst composition and operating conditions.

As a final note, the distribution of cracked products was observed to be markedly different (Figures SI4 and SI5). Secondary cracking was more extensive over NiMoS/(HUSY $\left.+\mathrm{Al}_{2} \mathrm{O}_{3}\right)$ than over Pt/HUSY and the isomerization degree was also lower (vide SI.6 for discussion). Therefore, when it comes to cracking products, regardless of the good balance between catalytic functions, the gap in the reaction temperatures dictated a different product distribution.

\section{Discussion}

In this section, the differences between the laboratorial and the industrial-like catalytic systems are analysed at the active sites and mechanistic level. For comparison purposes, an in-between catalytic system, representing a step in the scaling-up of a hydrocracking catalyst (hence denominated "pilot"), was also included. In this system, the HDH function was Pt (as in the academic-like one), but it was deposed in the shaped HUSY support and located on the alumina phase (as in the industrial-like one) ${ }^{45}$. In that case, the catalyst was evaluated in pure $n$-hexadecane hydroconversion, i.e. in the absence of any contaminants like $\mathrm{H}_{2} \mathrm{~S}$ and $\mathrm{NH}_{3}$ (Table 4). Before the mechanistic considerations, the characteristics of NiMoS-based catalyst at the active site level are compared to those of platinum ones. Finally, the gained knowledge will 


\section{$1 \quad 6.1$ Hydrogenating-dehydrogenating function: Pt vs. NiMoS}

2 As mentioned in the Introduction, the hydrogenating function of a hydroconversion catalyst can

3 be granted either by a promoted transition metal sulphide or by a noble metal. The selection is

4 mainly determined by the low sulphur resistance of noble metals. Notwithstanding the fact that

5 both phases promote hydrogenation/dehydrogenation reactions, their active sites are

6 fundamentally different. For Pt-based catalysts, the active sites are surface $\mathrm{Pt}^{0}$ atoms, whilst, in

7 NiMoS-based catalysts, the active sites are Ni-promoted $\mathrm{MoS}_{2}$ sites. Moreover, the accessible

8 Pt sites can be easily probed through chemisorption methods whereas no routine

9 characterization method enables to probe the accessible NiMoS sites. In a previous work ${ }^{29}$, a

10 methodology to determine the number of NiMoS sites, based on amount of $\mathrm{Ni}$ engaged in

11 NiMoS phase, was developed. While this allows to finally quantify the amount of NiMoS sites, it

12 should be kept in mind that this corresponds to the overall sites and not only to the accessible

13 ones, as when measuring the chemisorption of probe molecule, e.g. $\mathrm{CO}$ on $\mathrm{Pt}^{0}$ sites.

The results revealed that Mo promoted sites (NiMoS) corresponded to only $15 \%$ of the overall Mo in the catalyst. Concomitantly, the deposition of Pt in either the HUSY zeolite or in the shaped extrudates leads to metal dispersions between $40^{27}$ and $90 \%{ }^{28,45,46}$, with shaped supports typically featuring higher dispersions. Potentially, because ionic exchange is preferred in the latter whereas incipient wetness impregnation is commonly employed in powder zeolites. Therefore, in NiMoS-based catalysts, the metal loading should be superior to that in Pt-based catalyst in order to achieve the same amount of $\mathrm{HDH}$ sites.

In this study, due to the documented low HDH activity of NiMoS sites compared to Pt sites, the difference was even made larger: Pt loading was $0.7 \%$ whereas Mo loading was $12 \%$. This gave rise to $\mathrm{HDH}$ sites concentrations in the catalysts of $20 \mu \mathrm{mol} \mathrm{g}{ }^{-1}$ and $280 \mu \mathrm{mol} \mathrm{g}{ }^{-1}$, respectively. Despite the potential overestimation of the concentration of accessible NiMoS sites might be overestimated to some extent by this technique, the NiMoS-based catalyst had more than 10-fold the $\mathrm{HDH}$ sites existing in Pt-based catalyst. More importantly, the preliminary tests (vide SI.4) indicated that apparently the Mo content cannot be used to tailor the activity of the $\mathrm{HDH}$ function as easily as in Pt catalysts.

\subsection{Metal-acid balance and intimacy}

Both hydrogenating functions were able to properly balance the zeolitic acid functions, according to the comparable turnover frequency over Brønsted sites and $\mathrm{C}_{16}$ isomers yields, but the metal to acid sites ratios differed enormously. Particularly, the plateau of maximal feed isomers yield was reached in Pt/zeolite catalysts for a metal to acid sites molar ratio of ca. 0.02 (at $543 \mathrm{~K}$ ) whilst, over NiMoS-catalysts, a metal to acid sites ratio of $1.3 \cdot 10^{3}$ was required (at $593 \mathrm{~K})$. Although the number of accessible NiMoS sites may have been somehow overestimated and tests occurred at higher reaction temperatures, the metal-to-acid sites ratio 
required was five orders of magnitude greater than the $\mathrm{n}_{\mathrm{Pt}} / \mathrm{n}_{\mathrm{Al}}$, clearly corroborating the

2 substantially greater hydrogenating activity of $\mathrm{Pt}^{0}$ sites compared to NiMoS sites, previously

3 referred in literature ${ }^{47,48}$.

4 In the investigated conversion range, similar yield in $\mathrm{C}_{16}$ isomers was reached for catalysts working at a temperature differing $65 \mathrm{~K}$. Although the low activity of the NiMoS catalyst did not allow for high conversion experiments, all evidence indicate that the reaction temperature does not affect the isomerisation selectivity when catalysts are well-balanced. This agrees with the unique feed isomer yield curve typically reported in literature over a relatively wide range of operating conditions for HUSY zeolite ${ }^{35,36}$. Furthermore, it points out a comparable activation energy of isomerization and cracking pathways, as already suggested in literature for particular cases ${ }^{35}$. Otherwise, the isomerization selectivity at a given conversion of well-balanced catalysts would be influenced by the reaction temperature.

The disclosure of a similar intrinsic behaviour of well-balanced zeolites in such dissimilar catalytic systems allowed several insights. First of all, despite the numerous steps during catalyst preparation (comprising shaping, metal deposition, and thermal treatments), the zeolite performance can be preserved by judiciously designing the experimental protocols. Furthermore, inhibition by ammonia of most of the acid sites only reduced the number of available sites, while their intrinsic performance was not affected. Conversely, reports in literature showing a beneficial effect of $\mathrm{NH}_{3}$ inhibition to selectivity have commonly attributed this to the suppression of the strongest acid sites. Herein, this effect was proposed to be mainly a consequence of the different degree of metal-acid balance, while the HUSY zeolite selectivity remained unchanged. This also supports the argument that selectivity of well-balanced HUSY zeolite is mainly determined by confinement effects ${ }^{49}$.

The number of acid-catalysed steps that may occur before hydrogenation depends also on the distance between $\mathrm{HDH}$ and acid sites ${ }^{15,16,45}$. For instance, in the pilot-like catalyst, with platinum nanoparticles located in the alumina binder, a lower maximal $\mathrm{C}_{16}$ isomers yield was observed. This was attributed to the longer distance between $\mathrm{HDH}$ and acid sites, as compared to $\mathrm{Pt} / \mathrm{HUSY}^{45}$. The critical Pt-Brønsted acid site distance was disclosed to be determined by the size of zeolite clusters which was in the $200-20000 \mathrm{~nm}$ range, being hence much larger than the typical distance between Pt particles. Herein, for NiMoS-based catalysts, the case is similar: NiMoS sites were located on the alumina and so the critical distance between NiMoS and Brønsted acid sites should still be half the size of zeolite clusters, so 100-10000 nm. Even though a similar longer distance would be expected for both shaped catalysts, either Pt or NiMoS based, no impact of the longer $\mathrm{HDH}$-acid sites distance was noticeable in the latter case. As a matter of fact, the requirement for the critical distance $(R)$ intimacy between $\mathrm{HDH}$ and acid sites, for a given support (i.e. fixed diffusivity, D) at fixed operating conditions (i.e. fixed olefins concentration, $[\mathrm{O}]_{\mathrm{eq}}$ ), is determined by the rate of the overall reaction rate, in this case the rate of consumption of $n$-hexadecane (Eq. 3) ${ }^{15}$. In well-balanced catalysts, as the HDH reactions 
are at equilibrium, the overall reaction rate is determined by the acid-catalysed reactions. In that way, the much lower activity of NiMoS-based catalysts, due to the significant inhibition of the

3 HUSY zeolite by $\mathrm{NH}_{3}$, compared to Pt-based ones could be at the origin of the irrelevance of

$4 \mathrm{HDH}$-acid sites distance in industrial-like system.

$$
R^{2}<\frac{[O]_{e q} D}{r_{\text {overall }}} \quad \text { Equation (3) }
$$

5

Table 4: Parameters controlling the performances (activity and isomerisation selectivity) of the 7 three catalytic systems in the hydroconversion of $n$-hexadecane.

\begin{tabular}{|c|c|c|c|}
\hline Catalytic system & $\begin{array}{l}\text { Academic } \\
{ }^{13} \& \text { this study }\end{array}$ & $\begin{array}{c}\text { Pilot } \\
45\end{array}$ & $\begin{array}{l}\text { Industrial } \\
\text { This study }\end{array}$ \\
\hline Support & Powder HUSY & Shaped $\mathrm{Al}_{2} \mathrm{O}_{3}+\mathrm{HUSY}$ & Shaped $\mathrm{Al}_{2} \mathrm{O}_{3}+\mathrm{HUSY}$ \\
\hline HDH function & $\mathrm{Pt}$ & $\mathrm{Pt}$ & NiMoS \\
\hline $\begin{array}{l}\text { Location of HDH } \\
\text { function }\end{array}$ & Zeolite & Alumina & Alumina \\
\hline $\begin{array}{l}\text { Metal-acid } \\
\text { intimacy }\end{array}$ & +++ & - & ++ \\
\hline $\begin{array}{l}\text { Metal-acid } \\
\text { balance }\end{array}$ & ++ & +++ & + \\
\hline $\begin{array}{l}\text { Limiting factor } \\
\text { of catalytic } \\
\text { performance }\end{array}$ & Balance & Intimacy & Balance \\
\hline \multirow{3}{*}{ Solutions } & \multirow{3}{*}{ Increasing Pt loadings } & $\begin{array}{c}\text { Deposition of Pt on } \\
\text { zeolite }\end{array}$ & $\begin{array}{c}\text { Increasing } \mathrm{NH}_{3} \text { inhibition } \\
\text { (e.g. lower reaction } \\
\text { temperature) }\end{array}$ \\
\hline & & \multirow{2}{*}{$\begin{array}{l}\text { Reducing the size of } \\
\text { zeolite clusters }\end{array}$} & $\begin{array}{c}\text { Reduction of zeolite } \\
\text { content }\end{array}$ \\
\hline & & & $\begin{array}{l}\text { Increase hydrogenating } \\
\text { capacity of HDH function }\end{array}$ \\
\hline
\end{tabular}

\section{$8 \quad 6.3$ Industrial applications}

9 From a performance point of view, the sole substantial modification from the academic to 10 industrial system was the catalytic activity: NiMoS-catalyst would require an increase of $125 \mathrm{~K}$ in 11 the reaction temperature to reach the same catalytic activity of Pt/zeolite catalyst. This much 12 lower activity in industrial-like catalytic system can be mostly attributed to the inhibition of more 13 than $99.4 \%$ of the Brønsted sites by ammonia. The concentrations of available acid sites at 14 stake (in the order of a few micromoles per zeolite gram) were about two orders of magnitude 15 lower than the $820 \mu \mathrm{mol} \mathrm{g}_{\text {zeolite }}{ }^{-1}$ in the HUSY zeolite and the typical concentration of Brønsted 16 sites over non-inhibited zeolites ${ }^{50}$. In addition, the dilution of the zeolite, in the "industrial" 17 catalyst, by both the binder and the metals introduced, also accounted for the reduction in the 18 activity (9-fold loss). The product of these two effects leads to an estimated loss in activity 19 between 1500 and 4500 times. From the catalyst point of view, enhanced activities in 20 hydroconversion industrial catalysts can be hence achieved by mitigating the acid sites 
inhibition, but the gain in activity would be followed by a loss in feed isomers yield. In other words, the small number of available Brønsted sites in industrial catalytic systems (as compared to bench) results in a far lower hydroconversion activity but enables, at the same time, an acceptable metal-acid balance in presence of a substantially weaker $\mathrm{HDH}$ function.

The presence of basic molecules in the feedstock ensures hence the proper balance between the catalytic functions of industrial catalysts. Furthermore, one may hint that, as long as the $\mathrm{HDH}$ function is granted by a promoted transition metal sulphide (i.e. a function with relatively weak hydrogenating activity), industrial catalysts will be restrained to a much lower activity than bench catalysts if an acceptable isomerization selectivity has to be granted. In fact, when necessary, more extended inhibition of the Brønsted sites by $\mathrm{NH}_{3}$ or lower zeolite contents can be used to improve the metal-acid balance and hence the isomerization selectivity.

In spite of the approach to the industrial operation (for VGO hydrocracking) in terms of operating conditions, some discrepancies still persisted (Table 1). These were tentatively filled in by taking into account the literature consensus on the role of each operating variable, as summarized in Table 5. It is worth mentioning that some relevant topics to industrial operation are still barely studied in open literature. Particularly, most accounts are on short and long chain paraffins and only a few studies have been devoted to the hydrocracking mechanism of complex naphthenic and aromatic molecules, and their mixtures ${ }^{12,46,51-54}$. Hence, the focus was herein put on the well-known effects of operating conditions on long chain $n$-paraffins hydrocracking.

The foreseeable effects point to opposite directions precluding a straightforward answer. However, the significant impact of temperature in metal-acid balance together with the expected higher reactivity of the industrial feedstock hint at a lower degree of metal-acid balance in industrial operation, as to compared to the tests performed in this study. Therefore, improvements on industrial catalyst performance might be achieved by more hydrogenating $\mathrm{HDH}$ functions, including improvements on molybdenum sulphides ${ }^{55}$, and/or by an optimal control of the metal-acid balance via a careful manipulation of the temperature. Playing with the acid site inhibitor partial pressure is also a possibility, but, due to the very high coverage of the acid sites, this is expected to have limited impact ${ }^{29}$.

Table 5: Differences and expected outcomes of modification of the operating conditions from the ones used in this work to VGO hydrocracking ones, for a given bifunctional catalyst.

\begin{tabular}{|c|c|c|c|c|}
\hline Parameter & Feedstock & $\mathrm{NH}_{3}$ partial pressure & Total pressure & Temperature \\
\hline Change & Longer paraffins & Increase & Increase & Increase \\
\hline \multirow[t]{2}{*}{ Effects } & \multirow[t]{2}{*}{$\begin{array}{c}\text { Greater reactivity } \\
\qquad 35,56\end{array}$} & \multirow{2}{*}{$\begin{array}{l}\text { Less available } \\
\text { Brønsted sites } \\
\text { (this study) }\end{array}$} & $\begin{array}{l}\text { Lower reactivity gap } \\
\text { between molecules } \\
57,58\end{array}$ & $\begin{array}{c}\text { More available } \\
\text { Brønsted sites } \\
\text { (this study) }\end{array}$ \\
\hline & & & $\begin{array}{l}\text { Superior metal-acid } \\
\text { balance }\end{array}$ & $\begin{array}{l}\text { Lower kinetic constant } \\
\text { ratio of } \mathrm{HDH} \text { to acid }\end{array}$ \\
\hline
\end{tabular}




\begin{tabular}{|c|c|c|c|c|}
\hline & & & & reactions $^{35}$ \\
\hline $\begin{array}{l}\text { Expected } \\
\text { outcome }\end{array}$ & $\begin{array}{l}\text { Superior activity } \\
\text { Inferior } \\
\text { isomerization } \\
\text { selectivity, due to } \\
\text { lower metal-acid } \\
\text { balance and, } \\
\text { potentially, low } \\
\text { intimacy }\end{array}$ & $\begin{array}{l}\text { Minor if Brønsted sites } \\
\text { are nearly saturated }\end{array}$ & $\begin{array}{l}\text { Unpredictable as } \\
\text { effects are } \\
\text { contradictory }\end{array}$ & $\begin{array}{l}\text { Superior activity } \\
\text { Inferior selectivity, } \\
\text { due to lower metal- } \\
\text { acid balance }\end{array}$ \\
\hline
\end{tabular}

1 Finally, the key role of temperature in the catalyst performance shall be taken into account when

2 designing and selecting catalysts for scale-up and industrialization. As the effect of temperature

3 depends on how balanced the catalyst is, it is strongly dependant on both the catalyst and the

4 operating conditions. Hence, in a first, more fundamental stage, the temperature effect shall be

5 suppressed in order to evaluate the catalyst intrinsic performance. During scale-up, the effect of

6 temperature shall be then thoroughly evaluated. Due to the numerous differences imposed by

7 the scale, extrapolation of relative performances from bench to industrial scale should be done

8 extremely cautiously.

\section{Conclusion}

The main goal of this work was to shed light at the parameters controlling the performance of industrial-like $\mathrm{NiMoS} /\left(\mathrm{Al}_{2} \mathrm{O}_{3}+\mathrm{HUSY}\right)$ hydrocracking catalysts, bridging the gap to the most academically studied Pt/HUSY ones. For the same reactants partial pressures but mimicking the presence of contaminants in the industrial case study (by co-feeding $\mathrm{H}_{2} \mathrm{~S}$ and $\mathrm{NH}_{3}$ ), wellbalanced industrial-like catalyst revealed to be as selective as the laboratorial one, but much less active (temperature gap at iso-conversion of $125 \mathrm{~K}$ ) due to the inhibition of most part of Brønsted sites by $\mathrm{NH}_{3}$. The turnover frequency per non-inhibited protonic site was however comparable to that of $\mathrm{Pt} / \mathrm{HUSY}$ catalysts. Hence, as long as the zeolite is not modified during catalyst preparation (comprising shaping and metal deposition), the zeolite intrinsic performance is not affected by the choice or location of $\mathrm{HDH}$ function, nor by the presence of $\mathrm{NH}_{3}$.

Concerning the $\mathrm{HDH}$-acid sites molar ratio, under the chosen operating conditions, both industrial-like and laboratorial-like catalysts could achieve the optimal balance between functions but the ratio of $\mathrm{HDH}$ to acid sites required was some orders of magnitude greater in NiMoS-catalysts the ones reached in Pt-based catalysts. Such extraordinarily high HDH to acid sites ratios over NiMoS-catalysts is mostly ensured by the partial inhibition of Brønsted sites. In that way, on may hint that, as long as the HDH function is granted by a promoted transition metal sulphide (i.e. a function with relatively weak hydrogenating activity), industrial catalysts will be restrained to a much lower activity than bench catalysts in order to keep an acceptable selectivity. 
In summary, ensuring optimal metal-acid balance and intimacy is critical to assess the intrinsic behaviour of bifunctional catalysts and achieve optimal performance in industrial applications.

Given the predominant role of the metal-acid balance in industrial-like conditions, the key parameters playing a role in the latter are temperature, via the inhibition of acid sites, and the hydrogenating function. Therefore, in addition to careful design of the operating conditions, the development of more efficient industrial catalysts shall focus not only on less diffusionrestrained acidic materials, but also on the engineering of more active hydrogenating functions, ensuring thereby the most out of the cutting-edge materials developed in the last decades.

\section{Acknowledgments}

The authors would like to thank G. Ribeiro for her expertise on the catalyst preparation; A. C. Gregório, G. Fernandes, J. Marin, L. Jacquet, and P.-Y. Alspektor for the work on the catalytic tests; and G. Pirngruber and E. Guillon for the fruitful discussions. Fundação para a Ciência e Tecnologia provided financial support through CQE (Project UID/QUI/00100/2013) and PhD grant (SFRH/BD/87927/2012).

\section{References}

1. Molecule Managers, European Chemical Industry Council, Online, 2019.

2. F. Bertoncini, A. Bonduelle-Skrzypczak, J. Francis and E. Guillon, in Catalysis by Transition Metal Sulphides, eds. H. Toulhoat and P. Raybaud, Ed. Technip, Paris, 2013, pp. 609-677.

3. P. Leprince, in Petroleum Refining, ed. J. P. Wauquier, Éditions Tecnhip, Paris, 2001, vol. 3.

4. M. Dekker, in Hydrocracking Science and Tecnhology, eds. J. Scherzer and A. J. Gruia, CRC Press, New York, 1996.

5. C. H. Bartholomew, Applied Catalysis A: General, 2001, 212, 17-60.

6. A. Corma and A. Martinez, in Zeolites and Ordered Mesoporous Materials: Progress and Prospects, eds. J. Cejka and H. VanBekkum, Elsevier Science Bv, Amsterdam, 2005, vol. 157, pp. 337-366.

7. V. M. Akhmedov and S. H. Al-Khowaiter, Catal. Rev.-Sci. Eng., 2007, 49, 33-139.

8. P. S. F. Mendes, J. M. Silva, M. F. Ribeiro, A. Daudin and C. Bouchy, Catalysis Today, 2019, DOI: https://doi.org/10.1016/i.cattod.2019.08.055.

9. H. Deldari, Applied Catalysis a-General, 2005, 293, 1-10. 
10. P. Maki-Arvela, T. A. K. Khel, M. Azkaar, S. Engblom and D. Y. Murzin, Catalysts, 2018, 8, 27.

11. H. L. Coonradt and W. E. Garwood, Industrial \& Engineering Chemistry Process Design and Development, 1964, 3, p. 38.

12. J. Weitkamp, Chemcatchem, 2012, 4, 292-306.

13. P. S. F. Mendes, J. M. Silva, M. F. Ribeiro, P. Duchêne, A. Daudin and C. Bouchy, AIChE Journal, 2017, 63, 2864-2875.

14. F. Alvarez, F. R. Ribeiro, G. Perot, C. Thomazeau and M. Guisnet, Journal of Catalysis, 1996, 162, 179-189.

15. P. B. Weisz, in Advances in Catalysis, eds. D. D. Eley, P. W. Selwood, P. B. Weisz, A. A. Balandin, J. H. De Boer, P. J. Debye, P. H. Emmett, J. Horiuti, W. Jost, G. Natta, E. K. Rideal and H. S. Taylor, Academic Press, 1962, vol. Volume 13, pp. 137-190.

16. N. Batalha, L. Pinard, C. Bouchy, E. Guillon and M. Guisnet, Journal of Catalysis, 2013, 307, 122-131.

17. C. Bouchy, G. Hastoy, E. Guillon and J. A. Martens, Oil \& Gas Science and Technology-Revue D Ifp Energies Nouvelles, 2009, 64, 91-112.

18. M. J. Angeles, C. Leyva, J. Ancheyta and S. Ramírez, Catalysis Today, 2014, 220-222, 274-294.

19. M. A. Ali, T. Tatsumi and T. Masuda, Applied Catalysis a-General, 2002, 233, 77-90.

20. M. A. Camblor, A. Corma, A. Martinez, V. Martinez-Soria and S. Valencia, Journal of Catalysis, 1998, 179, 537-547.

21. K. Sakashita, T. Kimura, M. Yoshino and S. Asaoka, Journal of the Japan Petroleum Institute, 2011, 54, 320-330.

22. R. Henry, M. Tayakout-Fayolle, P. Afanasiev, C. Lorentz, G. Lapisardi and G. Pirngruber, Catalysis Today, 2014, 220, 159-167.

23. C. Manrique, A. Guzmán, J. Pérez-Pariente, C. Márquez-Álvarez and A. Echavarría, Microporous Mesoporous Mat., 2016, 234, 347-360.

24. Q. Zhao, B. Qin, J. Zheng, Y. Du, W. Sun, F. Ling, X. Zhang and R. Li, Chemical Engineering Journal, 2014, 257, 262-272.

25. C. R. Marcilly, Top. Catal., 2000, 13, 357-366.

26. J. C. Chavarria, J. Ramirez, H. Gonzalez and M. A. Baltanas, Catalysis Today, 2004, 98, 235-242.

27. P. S. F. Mendes, G. Lapisardi, C. Bouchy, M. Rivallan, J. M. Silva and M. F. Ribeiro, Applied Catalysis A: General, 2015, 504, 17-28.

28. P. S. F. Mendes, J. M. Silva, M. F. Ribeiro, A. Daudin and C. Bouchy, Journal of Industrial and Engineering Chemistry, 2018, 62, 72-83. 
29. P. S. F. Mendes, J. M. Silva, M. F. Ribeiro, C. Bouchy and A. Daudin, Journal of Industrial and Engineering Chemistry, 2019, 71, 167-176.

30. P. S. F. Mendes, A.-L. Taleb, A.-S. Gay, A. Daudin, C. Bouchy, J. M. Silva and M. F. Ribeiro, Journal of Materials Chemistry A, 2017, 5, 16822-16833.

31. C. Marcilly, Acido-basic catalysis, Ed. Technip, Paris, 2005.

32. M. J. Girgis and Y. P. Tsao, Industrial \& Engineering Chemistry Research, 1996, 35, 386-396.

33. V. Calemma, S. Peratello and C. Perego, Applied Catalysis a-General, 2000, 190, 207218.

34. R. T. Hanlon, C. R. Kennedy, R. A. WARE and S. S. Wong, Studies in Surface Science and Catalysis, 1993, 75, 2423-2426.

35. J. W. Thybaut, C. S. L. Narasimhan, J. F. Denayer, G. V. Baron, P. A. Jacobs, J. A. Martens and G. B. Marin, Industrial \& Engineering Chemistry Research, 2005, 44, 5159-5169.

36. M. Steijns, G. Froment, P. Jacobs, J. Uytterhoeven and J. Weitkamp, Industrial \& Engineering Chemistry Product Research and Development, 1981, 20, 654-660.

37. C. Legens and P. Raybaud, in Catalysis by Transition Metal Sulphides, eds. H. Toulhoat and P. Raybaud, Ed. Technip, Paris, 2013, pp. 259-300.

38. S. Brunet, D. Mey, G. Pérot, C. Bouchy and F. Diehl, Applied Catalysis A: General, 2005, 278, 143-172.

39. B. Liu, Y. Chai, Y. Li, A. Wang, Y. Liu and C. Liu, Fuel, 2014, 123, 43-51.

40. E. Devers and S. Brunet, in Catalysis by Transition Metal Sulphides, eds. H. Toulhoat and P. Raybaud, Ed. Technip, Paris, 2013, pp. 579-608.

41. A.-F. Lamic, A. Daudin, S. Brunet, C. Legens, C. Bouchy and E. Devers, Applied Catalysis A: General, 2008, 344, 198-204.

42. S. Kasztelan and D. Guillaume, Industrial \& Engineering Chemistry Research, 1994, 33 , 203-210.

43. M. Bouchy, S. Peureuxdenys, P. Dufresne and S. Kasztelan, Industrial \& Engineering Chemistry Research, 1993, 32, 1592-1602.

44. C. Coutanceau, J. M. DaSilva, M. F. Alvarez, F. R. Ribeiro and M. Guisnet, Journal De Chimie Physique Et De Physico-Chimie Biologique, 1997, 94, 765-781.

45. P. S. F. Mendes, J. M. Silva, M. F. Ribeiro, A. Daudin and C. Bouchy, Submitted.

46. L. Brito, G. Pirngruber, E. Guillon, F. Albrieux and J. Martens, ChemCatChem, 2020, 12.

47. L. Leite, PhD thesis, Université Paris VI, 2000.

48. C. Flego and V. Calemma, US 0130554, 2003. 
49. E. Benazzi, L. Leite, N. Marchal-George, H. Toulhoat and P. Raybaud, Journal of Catalysis, 2003, 217, 376-387.

50. P. S. F. Mendes, F. M. Mota, J. M. Silva, M. F. Ribeiro, A. Daudin and C. Bouchy, Catalysis Science \& Technology, 2017, 7, 1095-1107.

51. J. W. Thybaut and G. B. Marin, in Advances in Catalysis, Vol 59, ed. C. Song, Elsevier Academic Press Inc, San Diego, 2016, vol. 59, pp. 109-238.

52. K. Sato, Y. Iwata, Y. Miki and H. Shimada, Journal of Catalysis, 1999, 186, 45-56.

53. S. G. A. Ferraz, B. M. Santos, F. M. Z. Zotin, L. R. R. Araujo and J. L. Zotin, Industrial \& Engineering Chemistry Research, 2015, 54, 2646-2656.

54. G. C. Laredo, P. Perez-Romo, J. Escobar, J. L. Garcia-Gutierrez and P. M. VegaMerino, Industrial \& Engineering Chemistry Research, 2017, 56, 10939-10948.

55. K. H. Kang, G. T. Kim, S. Park, P. W. Seo, H. Seo and C. W. Lee, Journal of Industrial and Engineering Chemistry, 2019, 76, 1-16.

56. J. F. Denayer, G. V. Baron, W. Souverijns, J. A. Martens and P. A. Jacobs, Industrial \& Engineering Chemistry Research, 1997, 36, 3242-3247.

57. B. D. Vandegehuchte, J. W. Thybaut, A. Martínez, M. A. Arribas and G. B. Marin, Applied Catalysis A: General, 2012, 441-442, 10-20.

58. J. F. M. Denayer, B. d. Jonckheere, M. Hloch, G. B. Marin, G. Vanbutsele, J. A. Martens and G. V. Baron, Journal of Catalysis, 2002, 210, 445-452. 